\title{
DO CANCELAMENTO SOCIAL À PRÁTICA DO LOBBY NO BRASIL: ALGUMAS REFLEXÕES JURÍDICAS
}

\author{
Thiago Alves Miranda ${ }^{1}$ \\ Marcelo Paar Santiago ${ }^{2}$ \\ Yasmin Juventino Alves Arbex ${ }^{3}$
}

RESUMO: O referido artigo traz uma breve abordagem acerca da forma, muitas vezes, desprezada com que a prática do lobby é vista no Brasil. Mostra que em outros países essa atividade é vista como uma prática comum e muitas vezes acertada por parte de interesses diversos. o objetivo deste artigo é fornecer informações sobre temas e questões relacionadas a essas atividades e seu impacto na sociedade. No entanto, no Brasil ainda existe uma relutância quanto ao lobby devido às possibilidades de sua prática serem voltadas para a corrupção ou interesses políticos que podem resultar em transtornos para o país ao invés de benefícios. Os resultados identificaram que o lobby ainda está muito longe de ser visto como uma atividade benéfica, restando, na atualidade apenas um pré-conceito gerado por parte da sociedade. O estudo foi feito por meio de uma pesquisa descritiva de cunho bibliográfico.

Palavras-chave: Lobby. Cancelamento social. Brasil. Atividade.

\section{INTRODUÇÃO}

De acordo com alguns conceitos, o lobby refere-se basicamente a um grupo de pessoas que tentam influenciar as decisões do governo para obter benefícios legais ou fiscais. $\mathrm{Na}$ verdade, esta atividade visa a defesa dos direitos junto aos representantes do governo. A origem do termo "lobby" vem do inglês, que significa salão, antessala.

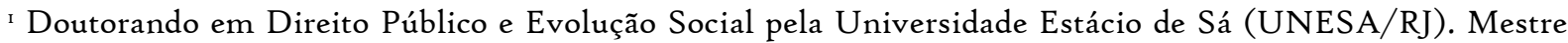
em Constitucionalismo e Democracia pela Faculdade de Direito do Sul de Minas (FDSM/MG). Licenciado em Pedagogia (IBRA/DF). Especialista em Neuropsicopedagogia (UCAM/RJ). Pesquisador visitante no grupo de pesquisa em Direitos Humanos e Vulnerabilidade pela Universidade Católica de Santos (UNISANTOS/SP). Diretor do Invictos Organização Educacional (Araguaína). Professor de Direito Constitucional da Faculdade de Ciências do Tocantins - FACIT. ORCID: https://orcid.org/oooo-ooo2-29o8o7o8 E-mail: tamiranda@yahoo.com

2 Bolsista do programa de desempenho do Doutorado em Direito Público e Evolução Social do PPGD-UNESA. Aluno externo do Doutorado em Finanças Públicas, Tributação e Desenvolvimento do PPGD/UERJ. Mestre em Direito Público e Evolução Social pelo PPGD-UNESA. Especialista no MBA em Licitações e Contratos administrativos pela UCAM. Especialista em Direito Tributário com ênfase em Legislação de Impostos pela UNESA. Pós-graduando em Gestão Tributária pela USP. Extensão em Práticas e Pesquisas Empíricas em Ciências Jurídicas e Sociais pela UFF. Graduado em Direito pela UGF. Pesquisador do Grupo de Pesquisa Núcleo de Pesquisa Justiça Administrativa em Contexto (NUPEJAC).marcelosantiagooi@hotmail.com ${ }_{3}^{3}$ Advogada. Consultora em Compliance de Dados na 9Stone Compliance. Especialista em Direito da Proteção e Uso de Dados. Especialista em Direito Processual. Mestre em Direito Social, Tutela Coletiva e Direitos Difusos. Doutoranda em Direitos Fundamentais e Novos Direitos. E-mail: alves.yasmin_@hotmail.com
} 
É neste espaço que fazendeiros e empresários do século XIX procuravam se aproximar dos parlamentares e falar sobre suas necessidades coletivas e pessoais. Com base nisso, buscou-se compreender com este artigo a seguinte questão: $O$ lobby deve ser considerado uma atividade legal para a empresa usufruir de suas vantagens?

A justificativa que permite a abordagem deste tema leva em consideração o fato de que o lobby é impopular no Brasil, justamente pela falta de esclarecimento e definição do seu verdadeiro significado e propósito, principalmente devido à falta de fiscalização das atividades do lobby no Brasil. Muitos países adotam essa abordagem, como nos Estados Unidos, em que ela é vista como parte do processo político e regulamentada por lei. O principal objetivo dos regulamentos do grupo de lobby é buscar transparência entre os grupos de interesse e o governo, e relatar publicamente o que está acontecendo entre eles. Sendo assim,

O método utilizado para a construção deste trabalho é um estudo qualitativo baseado em normas bibliográficas, por meio de obras e autores sobre temas relacionados. Na pesquisa bibliográfica, este modelo de pesquisa é realizado por meio de investigação e registros. Tendo em vista os conceitos propostos, este trabalho baseou-se na pesquisa bibliográfica, discussão publicados entre 2009 e 2021 na forma de: revistas, textos, artigos e livros. O método utilizado para conduzir a pesquisa é a dedução hipotética.

\section{${ }_{2}$ O LOBBY NO BRASIL E SUAS CARACTERÍSTICAS}

Segundo Carvalho (2009, p.44), lobby é “(...) a ação de influenciar o tomador de decisão na esfera do poder público. É a pressão exercida por um grupo de interesses”. Alguns autores apontam diferenças entre as definições de grupos de interesse e grupos de pressão e entendem que estas são o princípio básico para a compreensão do termo.

Segundo Santos e Cunha (2013), os grupos de interesse seriam forças sociais, profissionais, econômicas, que são organizados e atuantes, mas não dependem da atuação da pressão política. É uma atuação mais permanente e passiva. A partir do momento em que este mesmo grupo começa a agir em cima do governo reivindicando seus interesses, transforma-se em um grupo de pressão.

\subsection{Visão do conferp}


Segundo a Resolução Normativa nº 43, de 24 de agosto de 2002, do Conferp (Conselho Federal de Relações Públicas), é função do relações públicas: "desenvolver, implementar, montar, coordenar, dirigir, executar e avaliar serviço de relações governamentais, executar e coordenar atividades de Relações Governamentais lobby e cerimonial”. Para Farhat (2013), a regulamentação da profissão de lobista seria uma boa forma de coibir os maus usos e práticas antiéticas da profissão, visto que, no Brasil, se tem não só uma imagem negativa da atividade, mas a falta de regulamentação pode, talvez, ser a responsável pelo entendimento errôneo desta.

O autor menciona ainda que não considera que, para exercer a atividade de lobista, é necessária uma formação em Relações Públicas. No entanto, esse tipo de formação contribui com a produção de um conhecimento amplo que a área fornece, permitindo que esse profissional tenha o preparo devido, inclusive quanto a compreensão em áreas necessárias de conhecimento, como na Ciência Política, por exemplo (FARHAT, 2013).

\subsection{Visão do conrerp}

Santos e Cunha (2013) entendem que um conselho age pelo princípio da legalidade. Lobby é apenas uma das atividades do profissional de Relações Públicas que atua com Relações Governamentais. Portanto, não se trata de achar se Lobby é ou não função do RP, pois, legalmente, ela já está assim constituída. A respeito de tornar-se uma profissão regulamentada: ela diz que ela já está contemplada como atividade do profissional de Relações Públicas e acredita que o que deva ocorrer é a discussão sobre os limites éticos deste ofício. Cabe, também, aos Conselhos, a intensificação da fiscalização dos ditos lobistas.

Já os profissionais da comunicação entendem que são preferencialmente escalados para exercer as atividades de lobby devido ao seu entendimento sobre processos comunicativos, embora muitos advogados também sejam escolhidos para estas funções (CARVALHO, 2009).

\subsection{Origem da palavra}

$\mathrm{O}$ termo lobby tem sua origem na língua inglesa e significa antessala; saguão. $\mathrm{Na}$ Inglaterra, em que seu uso se popularizou, lobby indicava o local onde ficavam aqueles que 
abordavam políticos e autoridades, a fim de influenciá-los na aprovação de medidas nas quais tinham interesse (FARHAT, 2013).

Para Carvalho (2009), a palavra começou a ser empregada desta forma quando, no século XIX, o presidente dos Estados Unidos da época hospedou-se em um hotel, e pessoas interessadas em ganhar sua confiança costumavam lhe esperar na entrada deste. Já Farhat (2013) nos traz duas outras possíveis versões sobre esta origem: a primeira teria sido quando os agricultores do estado da Virgínia, nos EUA, utilizaram líderes para defenderem seus interesses quanto às políticas agrícolas da época. A segunda versão diz que teria começado também nos EUA, após as eleições de 1896, por meio da luta de classes.

\subsection{LOBBY EM OUTROS PAÍSES}

Nos Estados Unidos, o país mais avançado em termos de reconhecimento da profissão de lobista, desde 1946, esta é uma atividade regulamentada, trazendo, desta forma, um sistema de registro obrigatório que pretende garantir maior transparência para a área. Assim, a partir do conhecimento da sociedade das reais funções da profissão é possível a dissociação do termo com ideias ruins. Em 2009, havia 13.753 lobistas registrados no país, no entanto, acredita-se que apenas uma parcela dos profissionais está registrada (FARHAT, 2013).

Para esses registrados, é necessário o preenchimento, a cada quadrimestre, de relatórios financeiros, indicando o nome e o endereço do lobista e seus clientes, o quanto recebe e a descrição de todas as contribuições. A pena para quem descumprir as normas vai de multa até cinco anos de cadeia. Segundo a organização Center for Responsive Politics (CRP), que monitora as informações repassadas, por lei, pelas entidades e empresas ao Senado americano, a atividade movimentou US $\$ 3,3$ bilhões em 2012, sendo o setor farmacêutico o líder no volume de lobby, movimentando US $\$ 234$ milhões, 82 milhões de dólares a mais do que o segundo colocado, o setor de seguros (FARHAT, 2013).

$\mathrm{Na}$ União Europeia, esse registro dos lobistas é voluntário e há um código de conduta para orientar a atuação deles. O órgão responsável pela fiscalização das atividades é a Comissão Europeia, que pode suspender temporariamente o registro ou excluí-lo definidamente em caso de falhas severas ou reiteradas no cumprimento das regras do código de conduta. A Argentina e o Peru também têm o lobby como uma atividade regulamentada (CARVALHO, 2009). 


\subsection{REGULAMENTAÇÃO NO BRASIL}

Já no Brasil, há mais de vinte anos, tramita o projeto de lei (PLS 203/89), do exsenador Marco Maciel (DEM-PE), que visa regular a atividade de lobby no Congresso Nacional. Este projeto nunca chegou a ser colocado em votação no plenário. Desde sua criação, outras seis propostas sobre a regulamentação foram criadas e arquivadas posteriormente devido às urgências de outros projetos de cunho social (CARVALHO, 2009).

Algumas propunham regular por meio de uma resolução interna no congresso, e outras, como o projeto de lei (PL I.202/o7), propõem a regulamentação do lobby não só no Congresso, mas também nos órgãos do executivo. Todos os autores lidos para este trabalho argumentam que a proposta traria esclarecimentos sobre a profissão de lobista, visto que, no Brasil, há uma tendência de utilizar o termo lobby de uma forma pejorativa, sendo sinônimo de corrupção; suborno e possibilitaria estabelecer os limites da atividade (MANCUSO; GOZETTO, 20II).

\subsection{EXEMPLOS DE AÇÕES LOBISTAS}

Infelizmente no Brasil, quase todas as notícias que envolvem a palavra lobby, têm em seu conteúdo uma visão pejorativa da atividade. Dificilmente se emprega o termo para designar quaisquer tipos de pressões exercidas em cima de algum tomador de decisões. Como exemplo é possível citar duas publicações. A primeira, publicação ocorreu na Revista Veja, em o6 de agosto de 20II, em que o próprio título da reportagem: "Escândalo de lobby provoca primeira baixa na Agricultura" menciona um escândalo provocado por uma prática de lobby, que levou à baixa do então Ministro da Agricultura, Milton Ortolan. Foram divulgados detalhes das atividades que o lobista Júlio Froes exercia no ministério (MARQUES, 20II).

As funções do lobista eram basicamente fazer contatos e atuar em processos de licitação, editais etc. Ele foi acusado, junto com o secretário executivo, por inúmeras condutas irregulares de corrupção. A segunda notícia, publicada Revista Isto é, cita um lobista, Arthur Teixeira, que supostamente teria sido contratado pela Alstom e a Siemens para pagar propinas a agentes públicos a fim de obter contratos (RODRIGUES; MOURA; PARDELLA, 2013). 
Ambas são notícias que prejudicam toda e qualquer imagem positiva da atividade que se possa querer criar no brasil, pois utilizam o lobby de uma forma antiética e corrupta. Dessa forma, fica bem complicado trabalhar as possibilidades de lobby no Brasil, pois essa atividade ainda enfrenta grande resistência por parte da sociedade, prejudicando assim o lado positivo quanto ao seu entendimento (FARHAT, 2013).

\section{CONSIDERAÇÕES FINAIS}

No desenvolvimento deste trabalho percebeu-se o quanto é complicado tratar deste assunto. Muitos autores apoiam essa prática mostrando todos os benefícios que a prática de Lobby pode trazer para a sociedade. Muitos outros são contra essa prática, pois é vista de forma criminosa ainda.

Pode ser uma ferramenta acertada em muitos países, mas no Brasil ainda é vista como não viável por muitos, mesmo que seja regulamentada e reconhecida. O lobby é uma das principais portas para a corrupção política e lavagem de dinheiro.

Autores questionam se apenas a regulamentação seria suficiente para separar o Lobby do tráfico de interesses. Será que no país do 'jeitinho brasileiro' essa regulamentação não abriria a oportunidade para os corruptos se intitularem como lobistas e praticarem ainda mais a corrupção diante dos nossos olhos, escondidos sob um crachá?

É preciso ter uma integração real com os órgãos de combate a corrupção, conseguindo dessa forma ampliar a transparência etc. Dessa forma, a regulamentação do Lobby é um tema que ainda merece destaque quanto à sua implantação, até mesmo quanto a sua conceituação, visando uma clareza maior de detalhes que permita com que essa prática seja realizada para fins benéficos que não envolvam atividades de corrupção. Agindo dessa forma será possível compreender a prática do lobby como uma atividade idônea na sociedade brasileira, assim como é vista e praticada em outros países.

\section{REFERÊNCIAS}

CARVALHO, Fagner dos Santos. O papel dos grupos de interesse e pressão na formatação e fortalecimento da democracia brasileira: o caso do departamento intersindical assessoria parlamentar (diap) durante o processo da constituinte (1987/1988) brasileira. In: Revista Aurora, Marília, v. 5, p. 32-39, dez. 2009. 


\section{CONSELHO FEDERAL DE RELAÇÕES PÚBLICAS (CONFERP). Resolução} Normativa no 43, de 24 de agosto de 2002. Brasília: Senado Federal, 2002.

FARHAT, Said. Lobby: o que é. como se faz. 3.ed. São Paulo: Aberje, 2013.

GIL, A. C. Como elaborar projetos de pesquisa. 4. ed. São Paulo: Atlas, 2010.

MANCUSO, W. P.; GOZETTO, A. O. Lobby: instrumento democrático de representação de interesses? In: Revista Organicom, v. 8, n. I4, 2011.

MARQUES, Luciana. Escândalo de lobby provoca primeira baixa na Agricultura. 20ir. In: Revista Veja. Edição de o6 de agosto de 20II. Disponível em: https://veja.abril.com.br/politica/escandalo-de-lobby-provoca-primeira-baixa-naagricultura/ Acesso em: 03/II/202I.

RODRIGUES, Alan; MOURA, Pedro Marcondes de; PARDELLAS, Sérgio. Corrupção em dose dupla. In: Revista Isto é. Edição no 2702, 29/10/2013.

SANTOS, Manoel Leonardo; CUNHA, Lucas. Percepções sobre a Regulamentação do Lobby no Brasil: convergências e divergências. Brasília: Ipea, 2015. 